\title{
How can transference-focused psychotherapy (TFP) help general psychiatrists working with patients with borderline personality disorder?
}

\author{
William Burbridge-James
}

\author{
COMMENTARY ON... MANAGING THE CLINICAL ENCOUNTER \\ WITH PATIENTS WITH BORDERLINE PERSONALITY DISORDER \\ IN A GENERAL PSYCHIATRY SETTING ${ }^{\dagger}$
}

\begin{abstract}
SUMMARY
Transference-focused psychotherapy concepts and techniques have much to offer experienced psychiatrists and psychiatrists in training in their work with patients with borderline personality disorder and, as a consequence, help address the stigmatisation of this group of patients and improve their clinical care.
\end{abstract}

\section{DECLARATION OF INTEREST}

W.B.-J. is chair of the Specialty Advisory Committee of the Faculty of Medical Psychotherapy, RCPsych, with governance for the content and delivery of the curriculum for psychotherapy training of trainee psychiatrists in the UK.

\section{KEYWORDS}

Personality disorders; borderline personality disorder; individual psychotherapy.

All psychiatrists can struggle in their interactions with patients with borderline personality disorder. It can often feel as if one is walking on a tight rope to maintain a working therapeutic alliance, where any difference between the patient's wishes and one's ability to provide for these threatens a catastrophe. In a clinical encounter, as vividly illustrated by Lee $\mathcal{E}$ Hersh (2019), it is this sudden movement, a fall from grace, from being at one moment an experienced helpful doctor-psychiatrist working alongside a patient to becoming an unhelpful inadequate denigrated doctor-psychiatrist the next, that makes negotiating the clinical encounter so perilous, threatening the clinician's professional potency and sense of identity and evoking negative attitudes towards this group of patients.

\section{Stigmatisation of personality disorder and attempts to address this}

Lee $\&$ Hersh reference recent research into psychiatric trainees' attitudes to personality disorder (Chartonas 2017) to illustrate this point and how little has changed over the 30 years since this was previously researched with experienced psychiatrists (Lewis 1988). This is despite centralised evidence-based policy efforts to address the problem through the Department of Health's guidance on the development of services for people with personality disorder (National Institute for Mental Health in England 2003a) and the Personality Disorder Capabilities Framework (National Institute for Mental Health in England 2003b). The Department of Health and Ministry of Justice also commissioned the Knowledge and Understanding Framework (https://kufpersonalitydisorder.org.uk/) to help people work more effectively with personality disorder, including the roll-out of accessible personality disorder awareness training. These initiatives were subsequently supported by National Institute for Health and Care Excellence (NICE) guidance on borderline personality disorder (NICE 2009a) and antisocial personality disorder (NICE 2009b) that aimed to guide commissioners and clinicians in principles of engagement and practicalities of providing effective interventions and services for people with personality disorder.

\section{Refocusing on the transference}

The article by Lee $\&$ Hersh helps refocus our attention as psychiatrists on addressing this
William Burbridge-James is chair of the Specialty Advisory Committee of the Faculty of Medical Psychotherapy at the Royal College of Psychiatrists. He is a consultant psychiatrist in medical psychotherapy with Essex Partnership University NHS Foundation Trust, and Training Programme Director for higher psychotherapy training in Health Education England's East of England region.

Correspondence Dr William Burbridge-James, The Taylor Centre, Warrior House, 42-82 Southchurch Road, Southend-on-Sea, Essex SS1 2LZ, UK. Email: william.burbridgejames@nhs.net

First received 27 Jan 2019 Accepted 25 Mar 2019

\section{Copyright and usage}

(C) The Royal College of Psychiatrists 2019.

${ }^{\dagger}$ See this issue. 
stigmatisation by expanding our knowledge base thus helping us develop our capacities to tolerate the vicissitudes of destabilising clinical encounters - and honing our skills through the application of the essential clinical techniques of transferencefocused psychotherapy (TFP).

Transference-focused psychotherapy as a specific modality may be less familiar to UK psychiatrists than mentalisation-based therapy (Bateman 2010) and dialectical behaviour therapy (Linehan 1987), the latter because of its evidence base in helping patients with borderline personality disorder where self-harm is prominent.

However, even if the fine grain of the conceptual framework of TFP is new ground, the essence of TFP may not be so unfamiliar to practising psychiatrists through their understanding of the transference during their exposure to psychodynamic psychotherapy in their training and the notion that what is not consciously expressed by the patient is repeated in the relationship with the doctor-psychiatrist (Freud 1914).

The contemporary understanding of object relations theory and helpful diagrammatic representation by Lee $\&$ Hersh deepen our understanding of the sudden shifts we can experience from idealised to denigrated object. They illustrate how these are related not only to the complexities of the patient's internalised past traumatic experiences with abusive others, which are to a degree ubiquitous in the background of people with borderline personality disorder, but also to defences against longed-for unmet dependency needs with a hoped-for idealised caregiver.

The unfortunate reality in the UK is that these dependency needs are also threatened through changes to the benefits system and pressures on mental health services (Bell 2013), which contribute to the impossible position that psychiatrists find themselves placed in.

\section{A dimensional approach to personality, levels of functioning and borderline personality organisation}

\section{Kernberg's dimensional model of personality disorder}

Lee \& Hersh introduce us to Otto Kernberg's dimensional model of personality disorder, which preceded proposed new approaches to personality assessment in ICD-11 and DSM-5 based on traits and levels of severity. The advantages and disadvantages of this shift in classification are described by Huprich (2018), who argues that we need a model that is trait-based but allows room for the categorical and is also dynamic and relational, incorporating Kernberg's concepts, and hence is more idiographic in essence.
Kernberg's model conceptualises personality along two continuous dimensions, a horizontal plane with introversion at one end and extroversion at the other, bisected by a vertical plane of levels of personality organisation, with neurotic at one end, borderline in the middle and psychotic at the other end. These levels of personality organisation are levels of severity that are evaluated on the basis of three factors: the person's reality testing; the person's sense of self and others; and the level of maturity of the person's defences.

\section{'Borderline personality organisation'}

'Borderline' is used in the sense of being in between neurotic and psychotic levels of functioning, rather than categorially. Hence, as Lee \& Hersh indicate, this allows for the understanding of clinical overlap for patients whose predominant traits may be of other personality disorders. Seen from this vertical perspective, 'borderline personality organisation' ('BPO'), with its fragile, easily threatened sense of self and potential for losing the capacity to reality test and retreating into primitive defence mechanisms, is a conceptualisation that I have found helpful in my clinical practice. This encompasses out-patient settings such as in the vignettes provided by Lee $\&$ Hersh, but also in-patient settings, where these aspects of 'BPO' may be most prominent and difficult to demarcate from psychotic illnesses. Understanding the impact of psychosocio-relational stressors on someone with 'BPO', alongside an understanding of insecure attachment relationships, can help the psychiatrist have a conceptual framework for understanding, for example, how potential discharge from an in-patient unit might lead to a dissociative presentation or an episode of self-harm: such a reaction might be seen not simply as an attempt to 'manipulate' others, which has a pejorative implication, but as a concrete attempt to test the boundaries of the self and to re-establish control over them, among other psychological functions and meanings.

\section{Using TFP techniques in the clinical encounter}

In their two vignettes Lee $\&$ Hersh clearly articulate TFP therapeutic techniques in the clinical encounter, especially attentiveness to nuances in 'the channels of communication': this can help us contain the negative transference of the patient by noticing our countertransference responses, which enable us to recognise the underlying affective quality of the communication. By being able to name the affect and, through the technique of 'naming the actors', attending to the dominant object relations dyad being played out at that moment, we can find words to talk to the patient in a timely sensitive way, help 
them feel understood and foster an alliance that is fundamental to psychotherapeutic psychiatric practice. Central to this is the clinician's ability to maintain 'therapeutic neutrality', and Lee \& Hersh illustrate how clinicians can get caught up in unhelpful personal interchanges - something we all have done. The structural understanding of TFP helps clinicians maintain a 'third position', where they can reflect on themselves in relation to the patient, a capacity described by Casement (1985) as the 'internal supervisor'.

\section{Instilling reflective capacity and the core components of psychodynamic psychotherapy}

Being able to develop a reflective capacity is one of the core aims of psychotherapy training for trainee psychiatrists in the UK and the USA. In the UK this is through participation in Balint groups and the 'being with' a patient in the psychotherapy long case that helps foster a reflective capacity as well as the capability to start to formulate responses to the patient that are attentive to the underlying unconscious scripts being enacted.

In the USA psychiatric residents have found using the TFP model helpful, because of its structured manualised approach, in 'strengthening understanding of core components of basic psychodynamic psychotherapy with all patients' (Bernstein 2015). Therefore, having this conceptual framework and understanding has the potential to expand our therapeutic capabilities in our day-to-day practice with patients with borderline personality disorder, which is at the heart of Lee $\&$ Hersh's article. It has much to offer both experienced clinicians and psychiatrists in training.

\section{References}

Bateman A, Fonagy P (2010) Mentalization based treatment for borderline personality disorder. World Psychiatry, 9: 11-5.

Bell D (2013) Mental IIIness and its Treatment Today. Centre for Health and the Public Interest

Bernstein J, Zimmerman M, Auchincloss EL (2015) Transference-focused psychotherapy training during residency: an aide to learning psychodynamic psychotherapy. Psychodynamic Psychiatry, 43: 201-21.

Casement $\mathrm{P}$ (1985) On Learning from the Patient. Routledge.

Chartonas D, Kyratsous M, Dracass S, et al (2017) Personality disorder: still the patients psychiatrists dislike? BJPsych Bulletin, 41: 12-7.

Freud S (1914) Remembering, Repeating and Working-Through (Further Recommendations on the Technique of Psycho-Analysis II). Reprinted (1953-1974) in the Standard Edition of the Complete Psychological Works of Sigmund Freud (trans \& ed J Strachey), vol. 12, pp. 145-7. Hogarth Press.

Huprich S (2018) Moving beyond categories and dimensions in personality pathology assessment and diagnosis. British Journal of Psychiatry, 213: 685-9.

Lee T, Hersh RG (2019) Managing the clinical encounter with patients with borderline personality disorder in a general psychiatry setting: key contributions from transference-focused psychotherapy. BJPsych Advances, this issue.

Lewis G, Appleby L (1988) Personality disorder: the patient's psychiatrists dislike. British Journal of Psychiatry, 153: 44-9.

Linehan MM (1987) Dialectical behavior therapy for borderline personality disorder: theory and method. Bulletin of the Menninger Clinic, 51: 261-76.

National Institute for Health and Care Excellence (2009a) Borderline Personality Disorder: Recognition and Management (Clinical Guideline CG78). NICE.

National Institute for Health and Care Excellence (2009b) Antisocial Personality Disorder: Prevention and Management (Clinical Guideline CG77). NICE.

National Institute for Mental Health in England (2003a) Personality Disorder: No Longer a Diagnosis of Exclusion. Policy Implementation Guidance for the Development of Services for People with Personality Disorder. NIMHE.

National Institute for Mental Health in England (2003b) Breaking the Cycle of Rejection: The Personality Disorder Capabilities Framework. NIMHE. 